\title{
Separation and characterization of individual mycolic acids in representative mycobacteria
}

\author{
Motoko Watanabe, ${ }^{1}$ Yutaka Aoyagi, ${ }^{1}$ Malin Ridell ${ }^{2}$ \\ and David E. Minnikin ${ }^{3}$ \\ Author for correspondence: Motoko Watanabe. Tel: +8188426 76 3040. Fax: +8188426763040. \\ e-mail: motokoko@ps.toyaku.ac.jp
}

\footnotetext{
1 School of Pharmacy, Tokyo College of Pharmacy and Life Science, 1432-1, Horinouchi, Hachioji, Tokyo 192-0392, Japan

2 Department of Medical Microbiology, University of Gothenburg,

Guldhedsgatan 10, S-41346

Gothenburg, Sweden

3 Department of Chemistry, University of Newcastle, Newcastle upon Tyne NE1 7RU, UK
}

Total mycolic acid methyl ester fractions were isolated from 24 representatives of Mycobacterium tuberculosis, Mycobacterium bovis (including BCG), Mycobacterium microti, Mycobacterium kansasii and Mycobacterium avium. The total mycolate functional group composition was estimated from ${ }^{1} \mathrm{H}-\mathrm{NMR}$ spectra. Mycolates were separated into $\alpha$-mycolates, methoxymycolates and ketomycolates and each class was further separated by argentation chromatography into mycolates with no double bonds, with one trans-double bond and with one cis-double bond. Mass spectrometry revealed the mycolate chain lengths and ${ }^{1} \mathrm{H}-\mathrm{NMR}$ the cis- and trans-double bond and cyclopropane ring content. The same species had similar mycolate profiles; the major type of each class had cis- or trans-cyclopropane rings and lacked double bonds. Minor proportions of possible unsaturated precursors of the cyclopropane mycolates were commonly encountered. Among unusual $\alpha$-mycolates, many strains had tricyclopropyl components with chains extended by 6 to 8 carbons.

Significantly, M. tuberculosis (Canetti) and $M$. avium had $\alpha$-mycolates with a trans-double bond and cyclopropane ring, whose chain lengths suggested a relationship to possible precursors of oxygenated mycolates. The methoxyand ketomycolates from a majority of $M$. tuberculosis strains had minor amounts of components with additional cyclopropane rings, some of whose chains were also extended by 6 to 8 carbons. These latter mycolates were major components in the attenuated $M$. tuberculosis H37Ra strain, whose mycolate profile was distinct from those of other strains of $M$. tuberculosis.

Keywords: mycobacterial mycolates, cyclopropane rings, double bonds, stereochemistry, tuberculosis

\section{INTRODUCTION}

Mycobacterial mycolic acids, whose general structures are indicated in Fig. 1, are high-molecular-mass 2-alkyl branched, 3-hydroxy fatty acids, which are characteristic components of the cell envelope of mycobacteria. Although they are present in the extractable lipids, mostly as trehalose dimycolates, the major portion is covalently bound in the cell envelope esterified to the 5hydroxy groups of arabinofuranosyl residues to form the terminal [5-mycoloyl- $\beta$-Araf- $(1 \rightarrow 2)-5$-mycoloyl- $\alpha$ Araf- $(1 \rightarrow)$ ] units of a major arabinogalactan polysaccharide (McNeil et al., 1991). The mycoloyl arabino-

Abbreviations: MAC, M. avium-intracellulare complex; MALDI-TOF/MS, matrix-assisted laser desorption ionization-time-of-flight mass spectrometry. galactan is, in turn, attached to the shape-forming peptidoglycan.

Schematic models of mycobacterial envelope structure have been proposed to show possible arrangements for the mycolic acids and other lipid components (McNeil \& Brennan, 1991; Minnikin, 1991; Paul \& Beveridge, 1994). According to the currently accepted structural model (Brennan \& Nikaido, 1995; Daffé \& Draper, 1998; Draper, 1998), the long hydrocarbon chains of the mycolic acids are arranged in an orderly fashion, in parallel, with the methyl ends towards the outside surface. This arrangement results in the electrontransparent layer of the cell envelope, the presence of which is revealed by electron micrographs of ultra-thin sections of mycobacterial cells (Paul \& Beveridge, 1992, 1994).

The mycolic acids usually have two intra-chain groups 


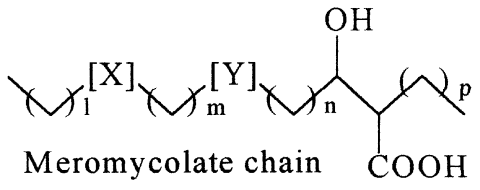

Type-1 mycolate
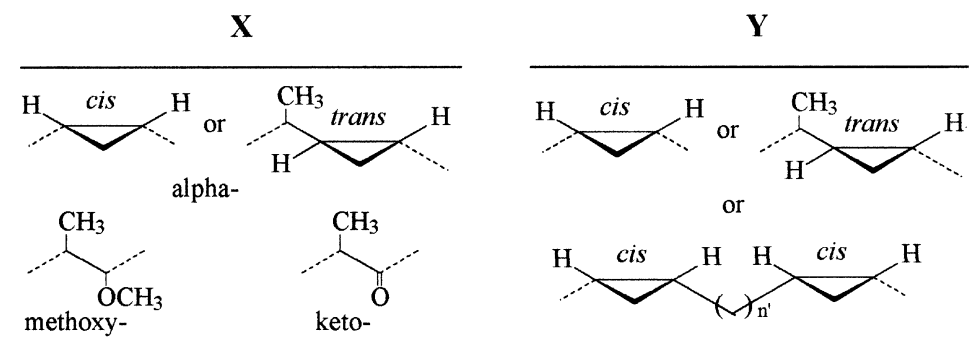

or

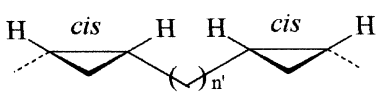

Type-2 mycolate

$\mathbf{X}$
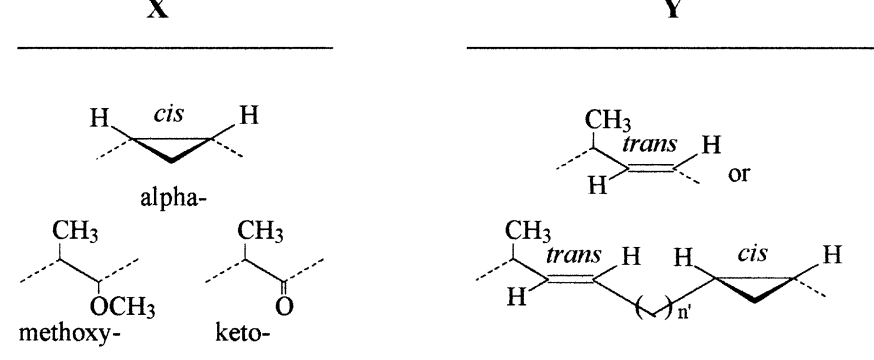

Type-3 mycolate
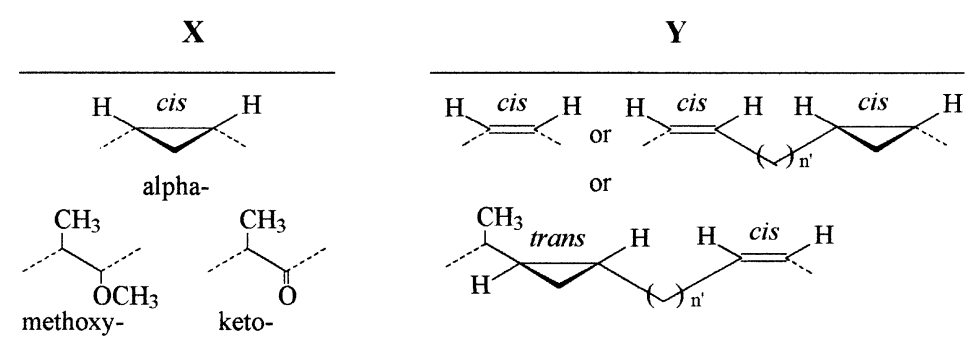

Fig. 1. Generalized structures of major mycobacterial mycolic acids, indicating possible combinations of intra-chain functional groups, $X$ and $Y$. Type-1 mycolates have no double bond, type-2 mycolates contain a trans-double bond and type-3 mycolates have a cis-double bond. The precise orientations of some of the $X$ and $Y$ groups are unknown, and in type- 2 and type- $3 \alpha$-mycolates $\mathrm{X}$ and $\mathrm{Y}$ may be reversed. in the major 'meromycolate' chain (Fig. 1), which vary in the type, stereochemistry and spacing. These functional groups will affect the packing of the long hydrocarbon mycolate chains, thereby influencing the intrinsic physiological functions of the cell envelope. Mycolic acids are major components of the mycobacterial cell envelope, amounting to as much as $34 \%$ by weight of the cell wall skeleton in Mycobacterium microti (Davidson et al., 1982), for example.

A true understanding of the importance of mycolic acids in cell envelope structure cannot be achieved until complete knowledge is established regarding the composition and the nature of the individual components of mycolic acids. Most previous studies have simply characterized the major mycolic acids in certain species (Davidson et al., 1982; Qureshi et al., 1978) or recorded the general distribution of mycolate types, the essential functional groups and the range of chain lengths of mycolic acids in representative mycobacteria (Minnikin et al., 1984a).
In the present study, detailed assays of the composition and structure of mycolic acids from representative mycobacteria were performed, following normal-phase silica gel and argentation chromatographic separation into individual components. Each of the separated component mycolates was assayed by ${ }^{1} \mathrm{H}-\mathrm{NMR}$ spectrometry and matrix-assisted laser desorption ionization-time-of-flight mass spectrometry (MALDITOF/MS) to reveal the stereochemistry of the double bonds and cyclopropane rings and their chain lengths. The ratios between the $\alpha$-, methoxy- and ketomycolates in those mycobacteria were also estimated on the basis of the ${ }^{1} \mathrm{H}-\mathrm{NMR}$ spectra.

\section{METHODS}

${ }^{\mathbf{1}} \mathrm{H}-\mathrm{NMR}$ and mass spectra. ${ }^{1} \mathrm{H}-\mathrm{NMR}$ spectra $\left(\mathrm{CDCl}_{3}\right)$ were recorded on a Bruker AM400 $(400 \mathrm{MHz})$ and MALDITOF/MS (matrix : 2,5-dihydroxybenzoic acid) on a PerSeptive Biosystems Voyager Rs, in reflector mode. EI/MS was used to identify the size of the alkyl chain in the 2-position. 


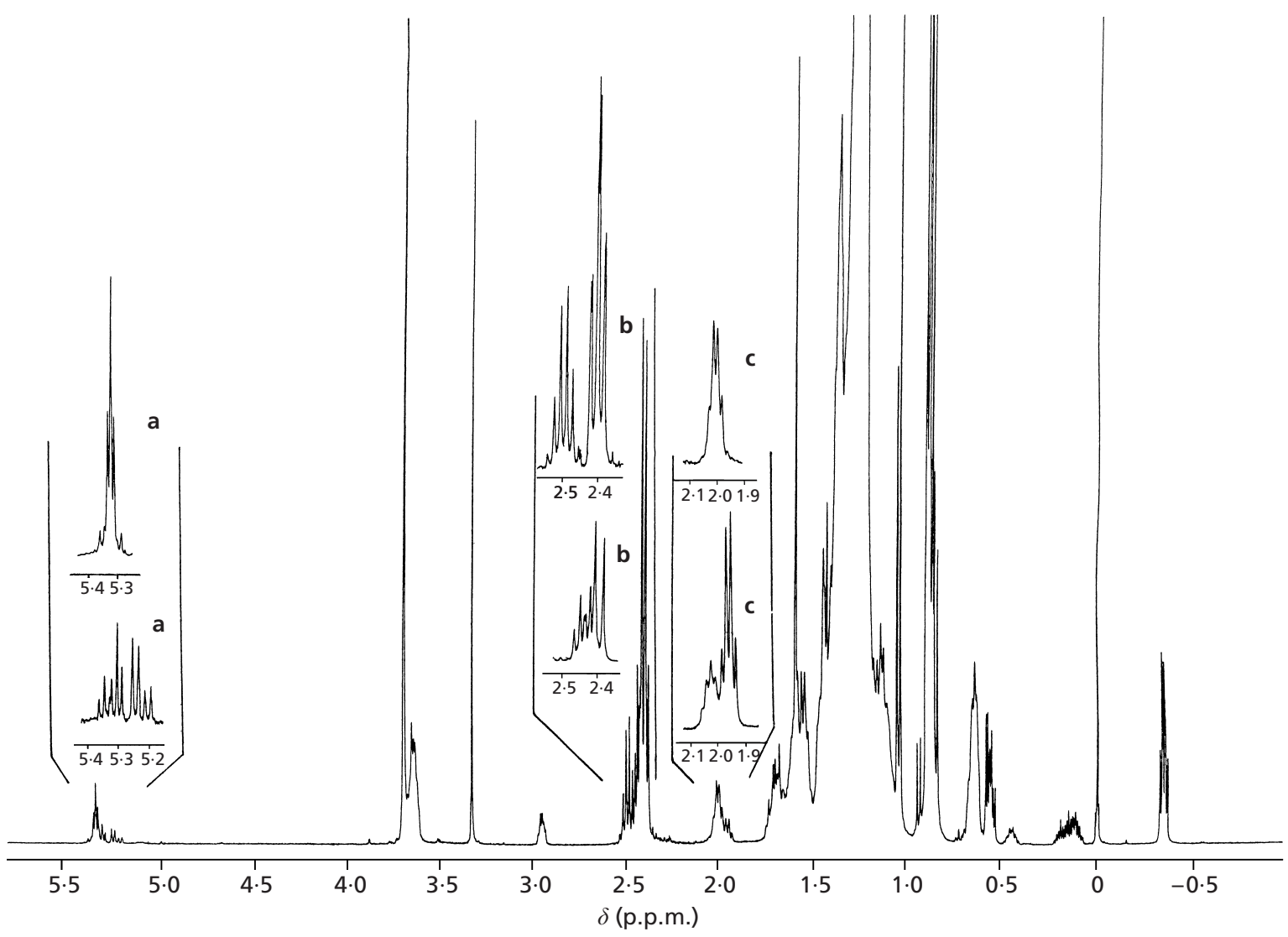

Fig. 2. ${ }^{1} \mathrm{H}$-NMR spectrum of the total mycolic acid methyl esters from $M$. bovis $\mathrm{BCG}^{\mathrm{N}}$ Tokyo, in $\mathrm{CDCl}_{3}$. Complex signals are magnified: a, cis-olefinic protons, a', trans-olefinic protons, b, protons for methylene and methine groups adjacent to keto carbonyls, b', protons on $\mathrm{C} 2$ and $\mathrm{C} 3-\mathrm{OH}$, c, protons for methylene groups adjacent to cis-double bonds, $\mathbf{c}^{\prime}$, protons for methylene and methine groups adjacent to trans-double bonds.

Silica gel column chromatography and TLC. The silica gel used for column chromatography was $40-50 \mu \mathrm{m}$ spherical beads (Kanto Kagaku, Japan). For preparative TLC, Merck 5744 plates were used, with a $2 \%$ ethanolic spray solution of Rhodamine 6G for detection under UV light.

Argentation TLC. $\mathrm{AgNO}_{3}$-treated silica gel plates were prepared by treatment of precoated Merck 5744 silica gel plates with a $15 \%$ solution of $\mathrm{AgNO}_{3}$ in acetonitrile, followed by drying.

Cell materials. The mycobacteria used were 19 strains of the M. tuberculosis complex [M. tuberculosis including clinical isolates (10), M. bovis (2), M. bovis BCG (6), M. microti (1)], 3 strains of $M$. kansasii and 2 strains of the $M$. aviumintracellulare complex (MAC), as listed in Table 1. Of the $M$. tuberculosis strains, $\mathrm{O}$ and $\mathrm{K}$ were newly separated clinical isolates, subcultured on egg slants only three times before the present culture in Kirchner's medium (Watanabe et al., 1994). Aoyama B is a Japanese standard strain used for the preparation of PPD. Strains 9829/87, 4610/91 and 2668/92 were isolated from patients in Sweden, subcultured twice on Löwenstein-Jensen slants and once on solid Sauton's medium before mass cultivation on the latter.

Preparation of total mycolate fraction. The mycolic acid fractions were prepared from hexane-washed or chloroformwashed defatted dry cell mass by a modification of a previous method (Hamid et al., 1993). Briefly, the cell mass was heated in aqueous $15 \%$ tetrabutylammonium hydroxide at $70{ }^{\circ} \mathrm{C}$ overnight followed by centrifugation and extraction of the acidified hydrolysate with diethyl ether. Further alkaline hydrolysis of the washed residue with solutions of either tetrabutylammonium hydroxide or $\mathrm{NaOH}$ produced no additional mycolic acid, as shown by TLC. The diethyl ether extract was placed on a silica gel column, eluted first with hexane and then with a series of diethyl ether/hexane $6: 100$, $1: 9$ and $3: 7, \mathrm{v} / \mathrm{v})$ mixtures; the latter eluent gave mycolic acids. The crude mycolic acid fraction was treated with trimethylsilyldiazomethane (Aldrich) (Hashimoto et al., 1981) and the methyl mycolate fraction was subjected to silica gel column chromatography, eluting first with hexane and then with diethyl ether/hexane $(3: 7, \mathrm{v} / \mathrm{v})$ to give a purified total methyl mycolate fraction. For mycolate functional group assays, by ${ }^{1} \mathrm{H}-\mathrm{NMR}$, a part of the total methyl mycolate fraction was further purified by preparative silica gel TLC with the same solvent system.

Separation of component mycolates. The total methyl mycolate fraction was subjected to silica gel column chromatography eluting with diethyl ether/hexane $(6: 100, \mathrm{v} / \mathrm{v})$ to separate the mixture into $\alpha$-mycolate, methoxymycolate and ketomycolate. Care was taken to collect the whole of each class of mycolate, as the stereochemistry of double bonds and cyclopropane rings in mycolates tended to affect the elution 
Table 1. Distribution of functional groups in total mycolate fraction from representative mycobacteria on the basis of ${ }^{1} \mathrm{H}-\mathrm{NMR}$ spectra

\begin{tabular}{|c|c|c|c|c|c|}
\hline \multirow[t]{2}{*}{ Strain* } & \multicolumn{2}{|c|}{ Double bonds $\dagger$} & \multirow{2}{*}{$\begin{array}{c}\text { Cyclopropyls } \\
\text { cis:trans }\end{array}$} & \multicolumn{2}{|c|}{ Mycolate ratios $\ddagger$} \\
\hline & $\begin{array}{l}\text { Content } \\
(\%)\end{array}$ & Nature & & $\alpha:$ methoxy: keto & $\alpha:($ methoxy + keto $)$ \\
\hline M. $t b$ Aoyama $\mathrm{B}^{a}$ & $6 \cdot 0$ & $c / t$ & $1: 0 \cdot 18$ & $1: 0 \cdot 74: 0 \cdot 25$ & $1: 0 \cdot 99$ \\
\hline M. $t b \mathrm{MNC} 1397^{b}$ & $4 \cdot 0$ & $\mathrm{c} / \mathrm{t}$ & $1: 0 \cdot 11$ & $1: 0 \cdot 78: 0 \cdot 28$ & $1: 1 \cdot 06$ \\
\hline M. $t b \mathrm{O}^{a}$ & $5 \cdot 0$ & $\mathrm{c} / \mathrm{t}$ & $1: 0 \cdot 13$ & $1: 0 \cdot 49: 0 \cdot 10$ & $1: 0 \cdot 59$ \\
\hline M. $t b \mathrm{~K}^{a}$ & $5 \cdot 1$ & $\mathrm{c} / \mathrm{t}$ & $1: 0 \cdot 13$ & $1: 0 \cdot 50: 0 \cdot 13$ & $1: 0 \cdot 63$ \\
\hline M. $t b 9829 / 87^{c}$ & $9 \cdot 5$ & $\ll \mathrm{t}$ & $1: 0 \cdot 15$ & $1: 0 \cdot 63: 0 \cdot 34$ & $1: 0 \cdot 97$ \\
\hline M. $t b 4610 / 91^{c}$ & $6 \cdot 4$ & $c / t$ & $1: 0 \cdot 14$ & $1: 0 \cdot 72: 0 \cdot 29$ & $1: 1 \cdot 01$ \\
\hline M. $t b 2668 / 92^{c}$ & $9 \cdot 6$ & $c>t$ & $1: 0 \cdot 14$ & $1: 0 \cdot 57: 0 \cdot 40$ & $1: 0 \cdot 97$ \\
\hline M. $t b$ Canetti MNC1485 ${ }^{c}$ & $18 \cdot 0$ & $\ll \mathrm{t}$ & $1: 0 \cdot 19$ & $1: 0 \cdot 64: 0 \cdot 80$ & $1: 1 \cdot 24$ \\
\hline M. $t b \mathrm{H} 37 \mathrm{Rv}^{c}$ & $10 \cdot 7$ & $c>t$ & $1: 0 \cdot 14$ & $1: 0 \cdot 54: 0 \cdot 49$ & $1: 1 \cdot 03$ \\
\hline M. $t b \mathrm{H} 37 \mathrm{Ra}^{c}$ & $22 \cdot 2$ & cis & $1:<0 \cdot 01$ & $1: 0 \cdot 57: 0 \cdot 45^{a}$ & $1: 1 \cdot 02$ \\
\hline M. bovis $\mathrm{MNC}^{b}$ & $5 \cdot 9$ & $c \ll t$ & $1: 0 \cdot 17$ & $1: 0 \cdot 72: 0 \cdot 35$ & $1: 1 \cdot 07$ \\
\hline M. bovis $\mathrm{MNC} 7^{b}$ & - & - & $-:-$ & $1: 0 \cdot 65: 0 \cdot 30$ & $1: 0 \cdot 95$ \\
\hline M. bovis BCG Danish $1331^{d}$ & $12 \cdot 9$ & $\mathrm{c} / \mathrm{t}$ & $1: 0 \cdot 12$ & $1:<0 \cdot 01: 1 \cdot 80$ & $1: 1 \cdot 81$ \\
\hline M. bovis BCG Danish GB425 ${ }^{c}$ & $15 \cdot 3$ & $c>t$ & $1: 0 \cdot 09$ & $1: 0 \cdot 05: 1 \cdot 76$ & $1: 1 \cdot 81$ \\
\hline M. bovis BCG Danish $\mathrm{MNC}^{b}$ & $8 \cdot 4$ & $c / t$ & $1: 0 \cdot 24$ & $1:<0 \cdot 01: 1 \cdot 73$ & $1: 1 \cdot 74$ \\
\hline M. bovis BCG Glaxo 10- $\mathrm{F}^{d}$ & $8 \cdot 5$ & $c>t$ & $1: 0 \cdot 04$ & $1:<0 \cdot 01: 1 \cdot 80$ & $1: 1 \cdot 81$ \\
\hline M. bovis BCG Pasteur 1173-p2 $2^{d}$ & $9 \cdot 0$ & $c>t$ & $1: 0 \cdot 06$ & $1: 0 \cdot 04: 1 \cdot 46$ & $1: 1 \cdot 50$ \\
\hline $\begin{array}{l}\text { M. bovis BCG Tokyo } 172 \\
{\left[9 \text { days }^{d}\right.}\end{array}$ & - & - & $-:-$ & $1: 0 \cdot 60: 2 \cdot 96^{b}$ & $1: 3 \cdot 56$ \\
\hline $\begin{array}{l}\text { M. bovis BCG Tokyo } 172 \\
{[2 \text { weeks }]^{d}}\end{array}$ & - & - & $-:-$ & $1: 0 \cdot 94: 2 \cdot 59^{b}$ & $1: 3 \cdot 53$ \\
\hline $\begin{array}{l}\text { M. bovis BCG Tokyo } 172 \\
{[3 \text { weeks }]^{d}}\end{array}$ & $21 \cdot 0$ & $c>t$ & $1: 0 \cdot 17$ & $1: 0 \cdot 85: 2 \cdot 67$ & $1: 3 \cdot 52$ \\
\hline $\begin{array}{l}\text { M. bovis BCG Tokyo } 172 \\
{[4 \text { weeks] }}\end{array}$ & - & - & $-:-$ & $2 \cdot 38^{b}$ & $1: 3 \cdot 58$ \\
\hline M. bovis BCG Tokyo 172-V $\mathrm{V}^{e}$ & $18 \cdot 1$ & $c \gg$ & $1: 0 \cdot 18$ & $1: 0 \cdot 97: 2 \cdot 57$ & $1: 3 \cdot 54$ \\
\hline M. microti OV248 & $17 \cdot 2$ & $c>t$ & $1: 0 \cdot 12$ & $1: 0 \cdot 50: 1 \cdot 16$ & $1: 1 \cdot 66$ \\
\hline M. kansasii 20-01 ${ }^{d}$ & $10 \cdot 3$ & $c / t$ & $1: 0 \cdot 37$ & $1: 0 \cdot 49: 0 \cdot 68$ & $1: 1 \cdot 17$ \\
\hline M. kansasii $304^{d}$ & $8 \cdot 7$ & $\mathrm{c} / \mathrm{t}$ & $1: 0 \cdot 53$ & $1: 0 \cdot 50: 1 \cdot 00$ & $1: 1 \cdot 50$ \\
\hline M. kansasii $429^{d}$ & $7 \cdot 2$ & $\mathrm{c} / \mathrm{t}$ & $1: 0 \cdot 38$ & $1: 0 \cdot 46: 0 \cdot 78$ & $1: 1 \cdot 24$ \\
\hline M. avium complex KK41-24 ${ }^{d}$ & $30 \cdot 4$ & $\ll \mathrm{t}$ & $1: 0 \cdot 61$ & $1:-: 1 \cdot 71^{c}$ & $-:-$ \\
\hline M. avium complex $\mathrm{MNC}^{b}$ & $25 \cdot 0$ & $c<t$ & $1: 0 \cdot 75$ & $-:-:-$ & $-:-$ \\
\hline
\end{tabular}

*M. $t b$, M. tuberculosis. a, Strains obtained from Research Institute of Tuberculosis, Kiyose, Tokyo; surface cultured in Kirchner's medium at $37^{\circ} \mathrm{C}$ for 4 weeks. $b$, Cells surface cultured in Sauton's medium in Statens Seruminstitut, Copenhagen, Denmark; see Minnikin et al. (1984a). c, Cells surface cultured in Sauton's medium in the Department of Medical Microbiology, University of Gothenburg, Sweden; see also Minnikin et al. (1984a). d, Strains from Research Institute of Tuberculosis, Kiyose, Tokyo; shake cultured in Sauton's medium at $37^{\circ} \mathrm{C}$ for 3 weeks unless specified [figures in brackets represent cultivation period]. e, BCG Tokyo 172 cells which had grown at $42{ }^{\circ} \mathrm{C}$ were subcultured at $42{ }^{\circ} \mathrm{C}$, and then shake cultured in Sauton's medium at $37^{\circ} \mathrm{C}$ for 3 weeks. $f$, For culture conditions, see Davidson et al. (1982).

† 'Content' is percentage content per whole mycolate. cis means trans not positively detected; $\mathrm{c} \gg$, mostly cis; $\mathrm{c}>\mathrm{t}$, more cis than trans; $\mathrm{c} / \mathrm{t}$, cis/trans ratio about $1: 1 ; \ll \mathrm{t}$, mostly trans. Estimation on the basis of ${ }^{1} \mathrm{H}-\mathrm{NMR}$ signal shapes. - , Either the signal was not detected or measurement was not performed.

$\ddagger a$, Ratio of the weights recovered. The calculated ratio was $1: 0 \cdot 44: 0 \cdot 23$. See text. $b$, Estimation on the basis of HPLC. $c$, Mixture of ketomycolate and unhydrolysed wax-ester mycolate, in approximate ratio $0 \cdot 6: 1$.

rates in silica gel chromatography with diethyl ether/hexane (see below). For the MAC mycolates, tetrabutylammonium hydroxide hydrolysis gave an inseparable mixture of keto- and wax-ester mycolates, so the mixture was further hydrolysed according to Jenkins \& Goren (1986). Briefly, a keto- and wax-ester mycolate mixture $(100 \mathrm{mg})$ was heated at $80^{\circ} \mathrm{C}$ with 2-propanol $(2 \mathrm{ml})$ and crushed $\mathrm{KOH}(200 \mathrm{mg})$ in a sealed tube for $2 \mathrm{~h}$ and treated in the usual manner to obtain an acid fraction, which was methylated with trimethylsilyl diazomethane. The methyl ester fraction was then subjected to 

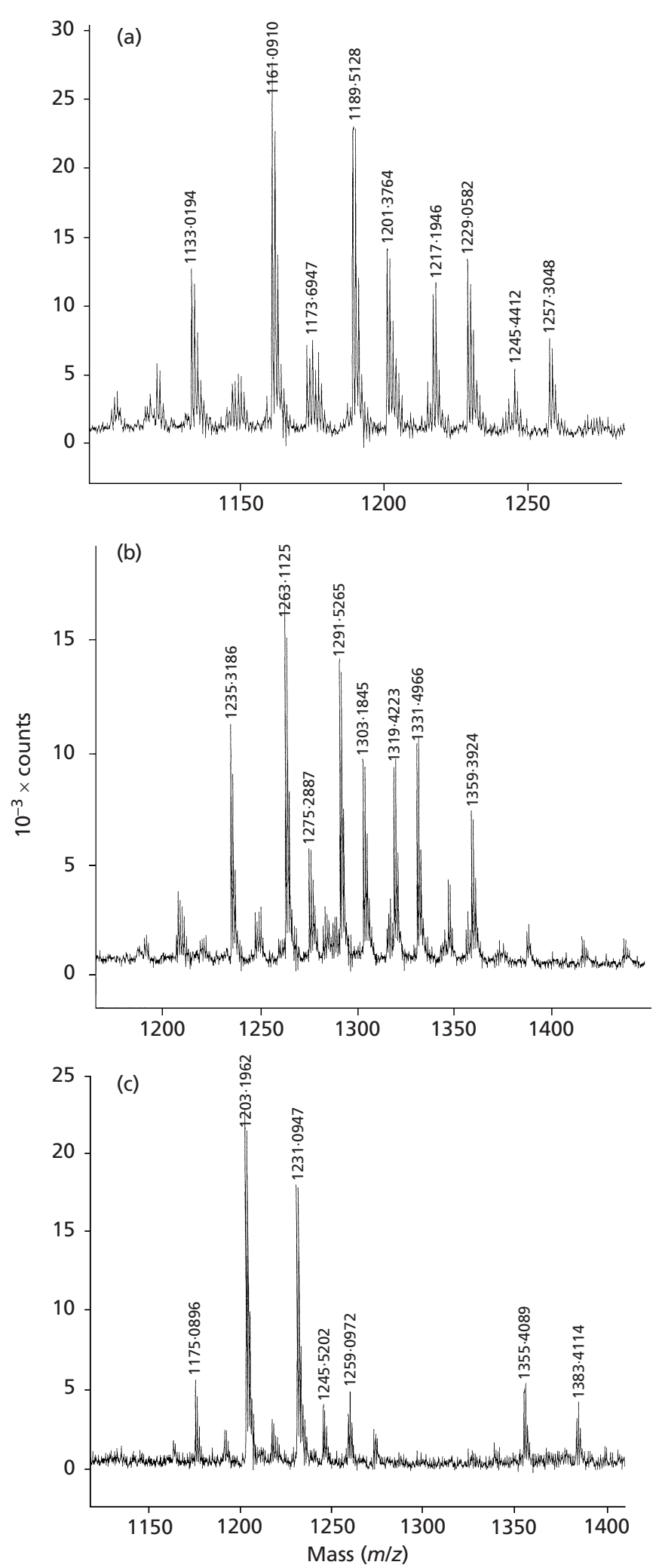

Fig. 3. MALDI-TOF/MS charts, in which all peaks are $[\mathrm{M}+\mathrm{Na}]^{+}$ ions. (a) $\alpha$-Mycolate- 3 of M. tuberculosis H37Ra (Table 2); one series $(m / z 1161,11891133,1217)$ is for $\alpha$-mycolate-3, having one cis-double bond and one cis-cyclopropane ring, and the other series $(\mathrm{m} / \mathrm{z} 1201,1229>1173,1257)$ is for mycolates with one cis-double bond and two cis-cyclopropane rings. (b) silica gel column chromatography, eluting with hexane/ethyl acetate $(10: 1, \mathrm{v} / \mathrm{v})$ to separate the resulting keto-, $\omega$-carboxymycolate and 2-alkanols. No further assays were conducted on the wax-ester mycolates.

Each of the $\alpha$-, methoxy- and ketomycolates was applied to $\mathrm{AgNO}_{3}$-treated silica gel TLC plates, respectively developed three to five times with $6: 100,8: 100$ and $1: 10(\mathrm{v} / \mathrm{v})$ diethyl ether/hexane mixtures. Each mycolate class was separated into type- 1 mycolate (mycolate-1, no double bonds), type- 2 mycolate (mycolate-2, one trans-double bond), and type- 3 mycolate (mycolate-3, one cis-double bond) (Fig. 1), as the top, middle and lowest bands, respectively. When the double bond content of the original material was very low or the amount of the mycolates available was very small, only the major type- 1 mycolates were separated and characterized.

Effect of cis/trans stereochemistry on mycolate chromatography. The methyl mycolate fraction (about $300 \mathrm{mg}$ ) of M. kansasii 304 was placed on a silica gel column $(22 \times 180 \mathrm{~mm})$ and diethyl ether/hexane $(6: 100, \mathrm{v} / \mathrm{v})$ eluates were collected in $20 \mathrm{ml}$ fractions. Each fraction was assayed for cis/trans-double bond and cis/trans-cyclopropane ring content by ${ }^{1} \mathrm{H}-\mathrm{NMR}$.

Estimation of mycolate compositions for each strain. The ratios between the $\alpha$-, methoxy- and ketomycolates in the total mycolate fractions were calculated by using the following equations, (1) and (2) or $\left(2^{\prime}\right)$. These equations assumed that the $\alpha$-mycolate contained two cyclopropane rings or one cyclopropane ring and one double bond, the methoxymycolate one methoxy group and one cyclopropane ring or one double bond, and the ketomycolate one keto group and one cyclopropane ring or one double bond. The bracketed abbreviations $\alpha, \mathrm{MeO}$ and Keto represent the content of $\alpha$-, methoxy- and ketomycolates, respectively, estimated from the area of each characteristic ${ }^{1} \mathrm{H}-\mathrm{NMR}$ signal.

(Double bond $)+$ (cyclopropane ring)

$$
=2(\alpha)+(\mathrm{MeO})+(\text { Keto })
$$

$[($ Methyl ester methyl protons $)+(\mathrm{C} 3-\mathrm{H})] / 4$

$$
\begin{aligned}
& \quad=(\alpha)+(\mathrm{MeO})+(\text { Keto }) \\
& (\mathrm{C} 2-\mathrm{H})+(\mathrm{C} 3-\mathrm{OH})+\left(\mathrm{CH} \text { and } \mathrm{CH}_{2} \text { next to keto }\right) \\
& \quad=2(\alpha)+2(\mathrm{MeO})+5(\text { Keto })
\end{aligned}
$$

\section{RESULTS}

\section{Characteristic mycolate ${ }^{1} \mathrm{H}-\mathrm{NMR}$ signals}

The ${ }^{1} \mathrm{H}-\mathrm{NMR}$ spectrum of the methyl mycolate fraction from M. bovis BCG (Tokyo strain) is shown in Fig. 2 for reference; component signal profiles for cis- and trans-

Methoxymycolate-1 of M. tuberculosis H37Ra (Table 3); one series $(m / z 1263>1235,1291,1319)$ is for mycolates with one methoxy and one cis-cyclopropane ring and another series $(\mathrm{m} / \mathrm{z}$ $1303,1331>1275,1359)$ is for those with one methoxy and two cis-cyclopropane rings. (c) $\alpha$-Mycolate- 1 of $M$. avium complex KK 41-24 (Table 2); a major series of peaks $(\mathrm{m} / \mathrm{z} 1203$ $>12311175,1259$ ) is for the components having two ciscyclopropane rings and a minor series $(m / z 1245>1217,1273)$ is for mycolates with one cis- and one trans-cyclopropane ring. In addition, there is another minor series of peaks $(\mathrm{m} / \mathrm{z} 1335$ $>1383$ ) with three cis-cyclopropane rings and an additional 152 atomic mass units, when compared to the major series $(\mathrm{m} / \mathrm{z}$ $1175,1203,1231,1259)$. 
Table 2. Distribution of cis- and trans-double bonds and cyclopropane rings in $\alpha$-mycolates

Abbreviations: M. tb, M. tuberculosis; p, l, m, n and n' refer to Fig. 1, db, di-substituted double bond; cy.prop, di-substituted cyclopropane ring; c, cis; t, trans. -, Sample not available, signals not detected or measurement not performed.

\begin{tabular}{|c|c|c|c|c|c|c|c|c|c|c|c|}
\hline \multirow[t]{2}{*}{ Strain } & \multicolumn{3}{|c|}{$\alpha$-Mycolate-mix } & \multicolumn{4}{|c|}{$\alpha$-Mycolate-1 $1 \dagger$} & \multicolumn{2}{|c|}{$\alpha$-Mycolate- $2 \dagger$} & \multicolumn{2}{|c|}{$\alpha-$ Mycolate $-3 \dagger$} \\
\hline & $\begin{array}{l}\mathrm{db} \\
(\%)^{*}\end{array}$ & $\begin{array}{l}\text { cy.prop } \\
\text { cis:trans }\end{array}$ & $p$ & $\begin{array}{l}\text { cy.prop } \\
\text { cis:trans }\end{array}$ & $\begin{array}{l}2 \mathrm{cy} . \\
1+\mathrm{m}\end{array}$ & & $\begin{array}{c}3 \text { c-cy.prop } \\
1+\mathrm{m}+\mathrm{n}+\mathrm{n}^{\prime} \\
(\%) \neq\end{array}$ & $\begin{array}{c}1 \mathrm{c} \text {-cy.prop }+1 \mathrm{t}-\mathrm{db} \\
1+\mathrm{m}+\mathrm{n}\end{array}$ & $\begin{array}{l}2 \text { c-cy.prop }+1 \mathrm{t}-\mathrm{db} \\
1+\mathrm{m}+\mathrm{n}+\mathrm{n}^{\prime}(\%) \neq\end{array}$ & $\begin{array}{c}1 \mathrm{c}-\mathrm{cy} \cdot \mathrm{prop}+1 \mathrm{c} \text {-db } \\
1+\mathrm{m}+\mathrm{n}\end{array}$ & $\begin{array}{l}2 \text { c-cy.prop }+1 \mathrm{c}-\mathrm{db} \\
1+\mathrm{m}+\mathrm{n}+\mathrm{n}^{\prime}(\%) \neq\end{array}$ \\
\hline $\begin{array}{l}\text { M. } t b \\
\text { Aoyama B }\end{array}$ & $5 \cdot 0$ & $1: 0$ & 23 & $1: 0$ & & $\underline{44,46>42,48}$ & $52,54(<)$ & - & - & - & - \\
\hline $\begin{array}{l}\text { M. } t b \\
\text { MNC1397 }\end{array}$ & $5 \cdot 0$ & $1: 0$ & 23 & $1: 0$ & & $\underline{44,46>42,48}$ & $52,54>56(<)$ & - & - & - & - \\
\hline M. $t b \mathrm{O}$ & 1.6 & $1: 0$ & 23 & $1: 0$ & & $44,46>42,48$ & $52,54(<)$ & - & - & - & - \\
\hline M. $t b \mathrm{~K}$ & $3 \cdot 0$ & $1: 0$ & 23 & $1: 0$ & & $44,46>42,48$ & $52,54>56(<)$ & - & - & - & - \\
\hline $\begin{array}{l}\text { M. } t b \\
9829 / 87\end{array}$ & $4 \cdot 0$ & $1: 0$ & 23 & $1: 0$ & & $\underline{44,46>42,48}$ & - & - & - & - & - \\
\hline $\begin{array}{l}\text { M. } t b \\
4610 / 91\end{array}$ & $5 \cdot 3$ & $1: 0$ & 23 & $1: 0$ & & $\underline{46>4448}$ & $54>52,56(<)$ & - & - & - & - \\
\hline $\begin{array}{l}\text { M. } t b \\
2668 / 92\end{array}$ & $6 \cdot 0$ & $1: 0$ & 23 & $1: 0$ & & $\underline{44,46>48}$ & $52>54>56(<)$ & - & - & - & - \\
\hline $\begin{array}{l}\text { M. } t b \\
\text { Canetti } \\
\text { MNC1485 }\end{array}$ & $\mathrm{c}<\mathrm{t} 6.7$ & $1: 0$ & 23 & $1: 0$ & & $\underline{44,46>42,48}$ & $52,54(<)$ & $\underline{49>51>47}$ & - & $\underline{46>44,48}$ & $46>44,48(18)$ \\
\hline $\begin{array}{l}\text { M. } t b \\
\text { H37Rv }\end{array}$ & $7 \cdot 6$ & $1: 0$ & 23 & $1: 0$ & & $\underline{44,46>48,50}$ & $52,54(<)$ & - & - & $\underline{44>42,46}$ & - \\
\hline $\begin{array}{l}\text { M. } t b \\
\text { H37Ra }\end{array}$ & $21 \cdot 2$ & $1: 0$ & 23 & $1: 0$ & & $\underline{46>44>48}$ & - & - & - & $\underline{44,46>42,48}$ & $44,46>42,48(43)$ \\
\hline $\begin{array}{l}\text { M. bovis } \\
\text { MNC8 }\end{array}$ & $2 \cdot 8$ & $1: 0$ & 23 & $1: 0$ & & $\underline{44>46,48>50}$ & - & - & - & - & - \\
\hline $\begin{array}{l}\text { M. bovis } \\
\text { MNC27 }\end{array}$ & $4 \cdot 4$ & 1:0 & 23 & $1: 0$ & & $\underline{46>44,48>50}$ & $52>54(<)$ & - & - & - & - \\
\hline $\begin{array}{l}\text { M. bovis } \\
\text { BCG } \\
\text { Danish } \\
1331\end{array}$ & $2 \cdot 4$ & $1: 0$ & 23 & $1: 0$ & & $44>46>48>42$ & - & - & - & - & - \\
\hline $\begin{array}{l}\text { M. bovis } \\
\text { BCG } \\
\text { Danish } \\
\text { MNC5 }\end{array}$ & $5 \cdot 2$ & $1: 0$ & 23 & $1: 0$ & & $\underline{44,46>48>42}$ & - & - & - & - & - \\
\hline $\begin{array}{l}\text { M. bovis } \\
\text { BCG Glaxo } \\
\text { 10-F }\end{array}$ & $3 \cdot 0$ & $1: 0$ & 23 & $1: 0$ & & $44>46>48>42$ & - & - & - & - & - \\
\hline $\begin{array}{l}\text { M. bovis } \\
\text { BCG } \\
\text { Pasteur } \\
1173 \text { P2 }\end{array}$ & $2 \cdot 0$ & $1: 0$ & 23 & $1: 0$ & & $44>46>48>42$ & $52>54(<)$ & - & - & $\underline{46>44>48}$ & - \\
\hline $\begin{array}{l}\text { M. bovis } \\
\text { BCG } \\
\text { Tokyo } 172\end{array}$ & $15 \cdot 3$ & $1: 0$ & 23 & $1: 0$ & & $\underline{44>46>48>42}$ & $\begin{array}{c}52>54>56> \\
50(<)\end{array}$ & - & - & $\underline{44,46>48}$ & - \\
\hline $\begin{array}{l}\text { M. bovis } \\
\text { BCG } \\
\text { Tokyo } \\
172-\mathrm{V}\end{array}$ & $28 \cdot 0$ & $1: 0$ & 23 & $1: 0$ & & $\underline{44>46>48>42}$ & $52>54(<)$ & - & - & $\underline{44,46>48}$ & - \\
\hline $\begin{array}{l}\text { M. microti } \\
\text { OV248 }\end{array}$ & $24 \cdot 0$ & $1: 0$ & 23 & $1: 0$ & & $\underline{44>46>42,48}$ & $52,54>56(<)$ & - & - & $\underline{46>44>48}$ & $44>42>40,46(12)$ \\
\hline $\begin{array}{l}\text { M. kansasii } \\
20-01\end{array}$ & $4 \cdot 4$ & $1: 0.02$ & 21 & $1: 0 \cdot 01$ & & $\underline{48>46,50}$ & $56>58(<)$ & - & - & - & - \\
\hline $\begin{array}{l}\text { M. kansasii } \\
304\end{array}$ & $5 \cdot 0$ & $1: 0 \cdot 04$ & 21 & $1: 0 \cdot 01$ & & $\underline{48>46,50}$ & - & - & - & - & - \\
\hline $\begin{array}{l}\text { M. kansasii } \\
429\end{array}$ & $5 \cdot 3$ & $1: 0.03$ & 21 & $1: 0 \cdot 01$ & & $\underline{48>46>50}$ & - & - & - & - & - \\
\hline $\begin{array}{l}\text { M. avium } \\
\text { complex } \\
\text { KK41-24 }\end{array}$ & $c<t 30.0$ & $\begin{array}{lll}0 & 1: 0 \cdot 09\end{array}$ & 21 & $1: 0 \cdot 10$ & $\underline{48>50>46,52}$ & $49>47,51 \mathbb{S}$ & $56>58(<)$ & $\underline{49>47,51}$ & - & $\underline{48,50>46,52}$ & $46,48>50(16)$ \\
\hline $\begin{array}{l}\text { M. avium } \\
\text { complex } \\
\text { MNC10 }\end{array}$ & $c<t 23 \cdot 0$ & $01: 0 \cdot 03$ & 21 & $1: 0 \cdot 05$ & $\underline{48>46.50}$ & $47>49 \mathbb{S}$ & $56>54,58(<)$ & $49>47>45,51$ & $57>55(<)$ & $\underline{48>46,50>44}$ & $48>46>44,50(16)$ \\
\hline
\end{tabular}

*Percentage in whole mycolate. $\mathrm{c}<\mathrm{t}$ means more trans-double bond than cis-double bond. Unless specified, the double bond is mostly cis-disubstituted.

†Each column gives chain lengths of the mycolates with the groups specified. In each series, the components are grouped in order of decreasing abundance. Major series are italicized and underlined.

$\ddagger$ Figures in parentheses are the percentage of three intra-chain group-containing species in each type of mycolate. $<$ denotes that the content was less than $10 \%$.

$\$$ Series containing one cis- and one trans-disubstituted cyclopropane ring. 
olefinic protons are also shown. The signals were assigned according to a previous study on the mycolic acids of MAC (Watanabe et al., 1999). The characteristic signals and coupling constants $(J$, in $\mathrm{Hz})$ for each mycolate or functional group were as follows. The signals for cis-double bond protons were at 5.36 p.p.m. $(2 \mathrm{H}, \mathrm{t}, J 4 \cdot 7)$ and those for the protons of two methylenes adjacent to cis-double bonds were at 2.02 p.p.m. $(4 \mathrm{H}, \mathrm{dt}$, $J 4 \cdot 7,6 \cdot 8)$. The signals for trans-double bonds were at $5 \cdot 22$ p.p.m. $(1 \mathrm{H}, \mathrm{dd}, J 15 \cdot 3,7 \cdot 4)$ and $5 \cdot 35$ p.p.m. $(1 \mathrm{H}, \mathrm{dt}$, $J 15.3,6.4$ ); the protons for the methylene and the methine groups, adjacent to trans-double bonds, were at 1.99 p.p.m. (2H, dt, $J 6.5,6.7)$ and 2.03 p.p.m. $(1 \mathrm{H}, \mathrm{m})$, respectively. The cis/trans ratios of double bonds given in Tables 1 to 5 were estimations from the shape of the signal profiles. The signals used for di-substituted cisand trans-cyclopropane rings were those for the highly shielded cis-cyclopropane ring proton at -0.34 p.p.m. $(1 \mathrm{H}, \mathrm{ddd}, J 4 \cdot 2,5 \cdot 3,5 \cdot 3)$ and those for the three transcyclopropane ring protons at 0.09-0.21 p.p.m. $(3 \mathrm{H}, \mathrm{m})$, respectively. The signal of the methoxy-methyl protons was at 3.34 p.p.m. $(3 \mathrm{H}, \mathrm{s})$ and that of the proton on the methoxy-bearing carbon was at $2 \cdot 97$ p.p.m. $(1 \mathrm{H}, \mathrm{m})$. The signals used for the keto group were those of the protons of methylene and methine groups adjacent to the keto carbonyl at 2.42 p.p.m. $(2 \mathrm{H}, \mathrm{dt}, J 7 \cdot 4,1.5)$ and at 2.50 p.p.m. $(1 \mathrm{H}, \mathrm{m})$, respectively. The signals for representing the whole amount of mycolate were the complex at 3.6-3.8 [methyl ester methyl protons (3.78 p.p.m., 3H, s) + C3-H (3.66 p.p.m., 1H, m)], and the signal at $2 \cdot 35-2.55$ p.p.m. [C2-H $(2 \cdot 43$ p.p.m., $1 \mathrm{H}$, $\mathrm{dt}, J 4 \cdot 4,5 \cdot 3)+\mathrm{C} 3-\mathrm{OH}(2 \cdot 38$ p.p.m., $1 \mathrm{H}, \mathrm{d}, J 8 \cdot 8)]$.

\section{Mycolate composition}

Calculations were performed from the above equations using the areas of the characteristic signals for each group. Thus, the signal area at $5 \cdot 18-5 \cdot 4$ p.p.m. $(\times 1 / 2)$ gave the double bond content, that at 3.34 p.p.m. $(\times 1 / 3)$ or at 2.97 p.p.m. gave the methoxymycolate content and those at -0.34 p.p.m. and at 0.19 $0 \cdot 25$ p.p.m. $(\times 1 / 3)$ gave the cis- and trans-cyclopropane ring content, respectively. Since the comparison is more accurate between signals of similar sizes, in a narrower magnetic field range, equation $\left(2^{\prime}\right)$ was used rather than (2). Thus, the signal area in the range of $2 \cdot 3-2.55$ p.p.m. represented the sum of the three protons adjacent to the ketomycolate keto group and the $\mathrm{C} 2-\mathrm{H}$ and of $\mathrm{C} 3-\mathrm{OH}$ protons represented the whole mycolate.

The calculated mycolate ratios are given in Table 1 , along with the number and type of double bonds and the cis/trans ratios of cyclopropane rings. The calculated ratios generally agreed well with the ratios of the weights of mycolates recovered from chromatography. For the mycolates of M. tuberculosis H37Ra, the weight ratio is given in Table 1, as it was different from the calculated ratio. Table 1 shows that there was some systematic variation in the ratios of $\alpha$-mycolate to total oxygenated mycolates (methoxymycolate + ketomycolate).
MALDI-TOF/MS proved to be a reliable procedure for determining the chain lengths of mycolic acid methyl esters and recognizing the presence of particular types of unsaturation and additional homologous series, as illustrated in Fig. 3 for representative mycolates. In general, homologous series, with 28 atomic mass unit differences, could be clearly distinguished for all classes of mycolates (Tables 2-4).

\section{Characteristics of $\alpha$-mycolates}

Table 2 shows the number and stereochemistry of the double bonds and cyclopropane rings in $\alpha$-mycolates, determined by ${ }^{1} \mathrm{H}-\mathrm{NMR}$. It also shows the chain lengths of the three components, $\alpha$-mycolate- 1 with no double bonds, $\alpha$-mycolate- 2 with a trans-double bond and $\alpha$ mycolate-3 with a cis-double bond. There was a clear difference between the chain lengths of $\alpha$-meromycolates of the M. tuberculosis complex and those of M. kansasii and MAC (Table 2).

In all strains tested, the major component was $\alpha$ mycolate- 1 containing two cyclopropane rings. These rings were $c$ is in the M.tuberculosis complex strains and cis, with a small amount of trans, in the $\alpha$-mycolates from MAC and M. kansasii. These major $\alpha$-mycolates from the M. tuberculosis complex strains had $1+\mathrm{m}+\mathrm{n}$ values in the range 42-50 (Table 2). In $\alpha$-mycolates- 1 , MALDI-TOF/MS often detected signals for a series of components, with an additional cyclopropane ring, which were larger than the major mycolates by 152 atomic mass units (Fig. 3c, Table 2).

Of the M. tuberculosis complex, only the Canetti strain gave substantial amounts of an $\alpha$-mycolate- 2 with a trans-double bond and these mycolates were slightly larger $(1+m+n=47-51)$. However, careful chromatographic separation and ${ }^{1} \mathrm{H}-\mathrm{NMR}$ analysis demonstrated that earlier chromatographic eluates of $\alpha$ mycolates from all $M$. tuberculosis strains, except H37Ra, contained a small amount of mycolates with trans-double bonds whose sizes were not determined (data not shown). The type- $2 \alpha$-mycolate is, however, a substantial characteristic component in the MAC strains (Table 2).

In the type- $3 \alpha$-mycolates, ${ }^{1} \mathrm{H}-\mathrm{NMR}$ showed that the cis-cyclopropane ring content per mycolate molecule was considerably higher than 1 . This implies the presence of species containing one cis-double bond and two cis-cyclopropane rings. These species were confirmed by MALDI-TOF/MS, as shown (Fig. 3a) for the type-3 $\alpha$-mycolates of $M$. tuberculosis H37Ra. The spectrum shows two series of peaks $(\mathrm{M}+\mathrm{Na})^{+}$for the components containing one cis-double bond and one cyclopropane ring (major peak, $m / z 1161$ ) and the other for the components containing one cis-double bond and two cis-cyclopropane rings (major peak, $m / z$ 1201). Type- $3 \alpha$-mycolates, with one cis-double bond and two cis-cyclopropane rings were limited to M. tuberculosis H37Ra and Canetti, M. microti and MAC; these strains, 
Table 3. Distribution of cis- and trans-double bonds and cyclopropane rings in methoxymycolates

Abbreviations: M. tb, M. tuberculosis; p, l, m, n and n' refer to Fig. 1; db, di-substituted double bond; cy.prop, di-substituted cyclopropyl; c, cis; t, trans; $\mathrm{c} \gg$, mostly cis; $\mathrm{c}>\mathrm{t}$, more cis than trans; $\mathrm{c} / \mathrm{t}$, cis/trans ratio about $1 / 1 ; \ll \mathrm{t}$, mostly trans. - , Sample not available, signals not detected or measurement not performed.

\begin{tabular}{|c|c|c|c|c|c|c|c|c|c|c|c|}
\hline \multirow[t]{3}{*}{ Strain } & \multicolumn{3}{|c|}{ Methoxymycolate mix } & \multicolumn{4}{|c|}{ Methoxymycolate-1 $1 \dagger$} & \multicolumn{2}{|c|}{ Methoxymycolate- $2 \dagger$} & \multicolumn{2}{|c|}{ Methoxymycolate- $3 \dagger$} \\
\hline & \multirow[t]{2}{*}{$\mathrm{db}(\%)^{*}$} & \multirow{2}{*}{$\begin{array}{l}\text { cy.prop } \\
\text { cis:trans }\end{array}$} & \multirow[t]{2}{*}{$\mathrm{p}$} & \multirow{2}{*}{$\begin{array}{l}\text { cy.prop } \\
\text { cis:trans }\end{array}$} & \multicolumn{2}{|c|}{1 cy.prop } & \multirow{2}{*}{$\begin{array}{c}2 \text { cy.prop } \\
1+\mathbf{m}+\mathbf{n}+\mathbf{n}^{\prime}(\%) \mathbb{S}\end{array}$} & \multirow{2}{*}{$\begin{array}{c}1 \mathrm{t}-\mathrm{db} \\
1+\mathrm{m}+\mathrm{n}\end{array}$} & \multirow{2}{*}{$\begin{array}{c}1 \mathrm{t}-\mathrm{db}+1 \text { cy.prop } \\
1+\mathbf{m}+\mathbf{n}+\mathbf{n}^{\prime}(\%) \mathbb{S}\end{array}$} & \multirow{2}{*}{$\begin{array}{c}1 \mathrm{c}-\mathrm{db} \\
1+\mathrm{m}+\mathrm{n}\end{array}$} & \multirow{2}{*}{$\begin{array}{c}1 \mathrm{c}-\mathrm{db}+1 \text { cy.prop } \\
1+\mathrm{m}+\mathbf{n}+\mathbf{n}^{\prime}(\%) \mathbb{S}\end{array}$} \\
\hline & & & & & $1+\mathrm{m}+\mathrm{n}(\mathrm{c}) \neq$ & $1+\mathbf{m}+\mathbf{n}(\mathbf{t}) \ddagger$ & & & & & \\
\hline M. $t b$ Aoyama B & $\ll \mathrm{t} 11 \cdot 3$ & $1: 0 \cdot 37$ & 23 & $1: 0 \cdot 48$ & $\underline{50>48,52}$ & $49,51>47,53$ & $58>56,60(<)$ & $\underline{49>51>47}$ & - & $\underline{50>48>52}$ & $50>48>52(20)$ \\
\hline M. $t b$ MNC1397 & $\mathrm{c} / \mathrm{t} 8.6$ & $1: 0 \cdot 27$ & 23 & $1: 0 \cdot 29$ & $\underline{50>48,52}$ & $49,51>53$ & $58>56,60(<)$ & $\underline{49>51>47}$ & $57>59>55(<)$ & $\underline{50>48,52}$ & $48,50>46>52(23)$ \\
\hline M. $t b \mathrm{O}$ & $\mathrm{c} / \mathrm{t} 12 \cdot 8$ & $1: 0 \cdot 45$ & 23 & $1: 0 \cdot 50$ & $\underline{50>48,52}$ & $49,51>47,53$ & $58>60(<)$ & $49>47,51$ & - & $50>48>46,52$ & $48,50>46(<)$ \\
\hline M. $t b \mathrm{~K}$ & $\mathrm{c} / \mathrm{t} 15 \cdot 0$ & $1: 0 \cdot 43$ & 23 & $1: 0 \cdot 48$ & $\underline{50>48,52}$ & $49,51>47$ & $58(<)$ & $\underline{49>47,51}$ & $57>55,59(<)$ & $\underline{50>48>46,52}$ & $48>46,50(17)$ \\
\hline M. $t b 9829 / 87$ & $c<t 13 \cdot 8$ & $1: 0 \cdot 38$ & 23 & $1: 0 \cdot 41$ & $50>52>48$ & $49>51>47$ & - & $\underline{49,51>47,53}$ & - & - & - \\
\hline M. $t b 4610 / 91$ & $<\mathrm{t} 8.7$ & $1: 0 \cdot 37$ & 23 & $1: 0 \cdot 40$ & $52>50>48,54$ & $51>49,53$ & - & $49,51>53$ & - & $50>48,52$ & $50>48>46>52(21)$ \\
\hline M. $t b 2668 / 92$ & $c<t 8.5$ & $1: 0 \cdot 26$ & 23 & $1: 0 \cdot 30$ & $\underline{50,52>48>54}$ & $51>49,53$ & $58>60(<)$ & - & - & - & - \\
\hline M. $t b$ Canetti MNC1485 & $\ll \mathrm{t} 26 \cdot 0$ & $1: 0 \cdot 34$ & 23 & $1: 0 \cdot 36$ & $\underline{52>50>48,54}$ & $51>49>53$ & $60>(<)$ & $\underline{51>49,53}$ & $59>57,61(<)$ & - & - \\
\hline M. $t b \mathrm{H} 37 \mathrm{Rv}$ & $\ll \mathrm{t} 12 \cdot 5$ & $1: 0 \cdot 32$ & 23 & $1: 0 \cdot 31$ & $\underline{50,52>48,54}$ & $51>49,53$ & $58>60(<)$ & $\underline{49>51>47,53}$ & $57>55,59(<)$ & $\underline{50>48,52>54}$ & $50>48,52(<)$ \\
\hline M. $t b \mathrm{H} 37 \mathrm{Ra}$ & $c \gg 22 \cdot 4$ & $1:$ trace & 23 & $1: 0 \cdot 01$ & $48>46,50,52$ & - & $48,50>46,52(33)$ & - & - & - & $48,50>46,52(100)$ \\
\hline M. bovis MNC8 & $c<t 10 \cdot 9$ & $1: 0 \cdot 39$ & 23 & $1: 0 \cdot 39$ & $\underline{48,50>52}$ & $49,51>53$ & - & $\underline{49>47,51}$ & - & $\underline{50>48>52}$ & $50>46,48,52(44)$ \\
\hline M. bovis MNC27 & $c<t 5.0$ & $1: 0 \cdot 46$ & 23 & $1: 0 \cdot 48$ & $\underline{50>52>48,54}$ & $51>49,53$ & - & - & - & - & - \\
\hline $\begin{array}{l}\text { M. bovis BCG Danish } \\
1331\end{array}$ & - & - & - & - & - & - & - & - & - & - & - \\
\hline $\begin{array}{l}\text { M. bovis BCG Danish } \\
\text { MNC5 }\end{array}$ & - & - & - & - & - & - & - & - & - & - & - \\
\hline M. bovis BCG Glaxo 10-F & - & - & - & - & - & - & - & - & - & - & - \\
\hline $\begin{array}{l}\text { M. bovis BCG Pasteur } \\
\text { 1173-P2 }\end{array}$ & - & - & - & - & - & - & - & - & - & - & - \\
\hline M. bovis BCG Tokyo 172 & $c>t 9 \cdot 2$ & $1: 0 \cdot 07$ & 23 & $1: 0 \cdot 07$ & $\underline{50>48,52}$ & $49>47,51$ & $58>60>56(14)$ & $\underline{49>47,51}$ & - & $\underline{50>48,52}$ & $48,50>46,52(30)$ \\
\hline $\begin{array}{l}\text { M. bovis BCG Tokyo } \\
172-\mathrm{V}\end{array}$ & $c>t 9.0$ & $1: 0 \cdot 05$ & 23 & $1: 0 \cdot 06$ & $\underline{50>48,52}$ & $49>$ & $58>56,60(13)$ & $\underline{49>47,51}$ & - & $\underline{50>48,52}$ & $50>48>52(42)$ \\
\hline M. microti OV248 & $c>t 8.6$ & $1: 0 \cdot 21$ & 23 & $1: 0 \cdot 21$ & $\underline{50,52>48,54}$ & $49,51>47,53$ & $58,60(<)$ & - & - & $\underline{50>48,52}$ & $50>48>52(45)$ \\
\hline M. kansasii 20-01 & $c>t 3.6$ & $1: 0 \cdot 59$ & 21 & $1: 0 \cdot 60$ & $\underline{50,52>48,54}$ & $51,53>49,55$ & - & $\underline{49>51>47}$ & - & - & - \\
\hline M. kansasii 304 & $\mathrm{c} / \mathrm{t} 5 \cdot 9$ & $1: 0 \cdot 58$ & 21 & $1: 0 \cdot 58$ & $\underline{52>50>48,54}$ & $51>49,53$ & $58,60>62(<)$ & - & - & - & - \\
\hline M. kansasii 429 & $c / t 4 \cdot 4$ & $1: 0 \cdot 64$ & 21 & $1: 0 \cdot 65$ & $\underline{50,52>48,54}$ & $51>49,53$ & $58>60(<)$ & - & - & - & - \\
\hline
\end{tabular}

*Percentage in whole mycolate.

†In each series, the components are grouped in order of decreasing abundance. Major series are italicized and underlined. The cyclopropane rings in methoxymycolates-2 and -3 appear to be predominantly cis. It was not possible to determine the stereochemistry of the additional cyclopropane ring in methoxymycolates- 1 .

‡(c) denotes cis-cyclopropane ring-containing series and $(\mathrm{t})$ denotes trans-cyclopropane ring-containing series.

$\$$ Figures in parentheses are percentages of three intra-chain group-containing species in each type of mycolate. $<$ denotes that the content is less than $10 \%$.

H37Rv and some BCG strains also had type-3 mycolates with one cis-double bond and one cis-cyclopropane ring (Table 2).

\section{Characteristics of methoxy- and ketomycolates}

In the methoxy- and ketomycolates, differences in the meromycolate chain lengths, as seen in the $\alpha$-mycolates, were not noted between the M. tuberculosis complex strains and the M. kansasii and MAC strains (Tables 3 and 4). The double bond content of the methoxy- and ketomycolates suggested that the major mycolates of these classes were also of type 1 , containing one oxygen function (methoxy or keto) and one cis- or transcyclopropane ring. The proportion of trans-cyclopropane rings was much higher in the ketomycolate-1 than in the methoxymycolate- 1 in all the strains tested, including M. tuberculosis H37Ra. However, the transcyclopropane ring content in H37Ra was quite low, with less than $1 \%$ in the methoxymycolate- 1 and less than $3 \%$ in the ketomycolate- 1 . As for $\alpha$-mycolates, cyclopropyl methoxy- and ketomycolates-1 were the major components; smaller amounts of type- 2 and -3 homologues containing one trans-double bond and one cisdouble bond, respectively, were also detected.

As in the case of $\alpha$-mycolate- 1 , in type- 1 and -2 methoxyand ketomycolates, MALDI-TOF/MS detected components which were heavier than the respective major mycolates by 152 atomic mass units and apparently contained an additional cyclopropane ring (Tables 3 and 4). The longer type- 1 and -2 methoxy- and ketomycolates had values $\left(1+m+n+n^{\prime}\right)$ around 57-60 in comparison with the $48-52$ values $(1+m+n)$ for the major type- 1 and -2 mycolates. However, the type- 3 methoxy- and ketomycolates, with an additional cyclopropane unit, were not elongated (Tables 3 and 4). ${ }^{1} \mathrm{H}$ NMR showed that, in the type- 3 mycolates of these classes, there was often a substantial proportion of cis- 
Table 4. Distribution of cis- and trans-double bonds and cyclopropane rings in ketomycolates

Abbreviations: M. tb, M. tuberculosis; p, l, m, n and n' refer to Fig. 1. db, di-substituted double bond; cy.prop, di-substituted cyclopropyl; c, cis; t, trans; $\mathrm{c} \gg$, mostly cis; c > t, more cis than trans; $\mathrm{c} / \mathrm{t}$, cis/trans ratio about $1 / 1$; $\ll \mathrm{t}$, mostly trans. - , Sample not available, signals not detected or measurement not performed.

\begin{tabular}{|c|c|c|c|c|c|c|c|c|c|c|c|}
\hline \multirow[t]{3}{*}{ Strain } & \multicolumn{3}{|c|}{ Ketomycolate mix } & \multicolumn{4}{|c|}{ Ketomycolate-1† } & \multicolumn{2}{|c|}{ Ketomycolate- $2 \dagger$} & \multicolumn{2}{|c|}{ Ketomycolate- $3 \dagger$} \\
\hline & \multirow[t]{2}{*}{$\mathrm{db}(\%)^{*}$} & \multirow{2}{*}{$\begin{array}{l}\text { cy.prop } \\
\text { cis:trans }\end{array}$} & \multirow[t]{2}{*}{$\mathrm{p}$} & \multirow{2}{*}{$\begin{array}{l}\text { cy.prop } \\
\text { cis:trans }\end{array}$} & \multicolumn{2}{|c|}{1 cy.prop } & \multirow{2}{*}{$\begin{array}{c}2 \text { cy.prop } \\
1+\mathbf{m}+\mathbf{n}+\mathbf{n}^{\prime}(\%) \mathbb{S}\end{array}$} & \multirow{2}{*}{$\begin{array}{c}1 \mathrm{t}-\mathrm{db} \\
1+\mathrm{m}+\mathrm{n}\end{array}$} & \multirow{2}{*}{$\begin{array}{c}1 \mathrm{t}-\mathrm{db}+1 \text { cy.prop } \\
1+\mathrm{m}+\mathrm{n}+\mathrm{n}^{\prime}(\%) \mathbb{S}\end{array}$} & \multirow{2}{*}{$\begin{array}{c}1 \mathrm{c}-\mathrm{db} \\
1+\mathrm{m}+\mathrm{n}\end{array}$} & \multirow{2}{*}{$\begin{array}{c}1 \mathrm{c}-\mathrm{db}+1 \text { cy.prop } \\
1+\mathrm{m}+\mathrm{n}+\mathrm{n}^{\prime}(\%) \mathbb{S}\end{array}$} \\
\hline & & & & & $1+\mathrm{m}+\mathrm{n}(\mathrm{c}) \neq$ & $1+\mathrm{m}+\mathrm{n}(\mathrm{t}) \neq$ & & & & & \\
\hline M. $t b$ Aoyama B & $c<t 18.6$ & $1: 3 \cdot 3$ & 23 & $1: 3 \cdot 3$ & $52>50>48$ & $\underline{51>49>53}$ & - & $\underline{49>51>47}$ & - & $\underline{50>48,52}$ & \\
\hline M. $t b$ MNC1397 & $c<t 12 \cdot 7$ & $1: 2 \cdot 0$ & 23 & $1: 2 \cdot 1$ & $52>50>48,54$ & $51>49>53$ & $59>57(<)$ & $49,51>47,53$ & $57,59>(<)$ & - & - \\
\hline M. $t b \mathrm{O}$ & $c<t 20 \cdot 0$ & $1: 2 \cdot 8$ & 23 & $1: 2 \cdot 8$ & $50,52>48,54$ & $\overline{49,51>47,53}$ & $59>57(<)$ & $49>47,51$ & - & $\underline{48,50>52}$ & $48,50>46>52(27)$ \\
\hline M. $t b \mathrm{~K}$ & $c<t 16 \cdot 3$ & $1: 3 \cdot 3$ & 23 & $1: 3 \cdot 3$ & $52>50>48,54$ & $\underline{51>49>47,53}$ & $59>57(<)$ & $\underline{49>47,51}$ & - & $\underline{50>48,52}$ & $48,50>52(13)$ \\
\hline M. $t b 9829 / 87$ & $\ll \mathrm{t} 25 \cdot 0$ & $1: 3 \cdot 2$ & 23 & $1: 3 \cdot 5$ & $52>50,54$ & $\underline{51>49,53}$ & $59>57(<)$ & $49,51>47,53$ & $57,59>55(<)$ & - & - \\
\hline M. $t b 4610 / 91$ & $c<t 13 \cdot 8$ & $1: 2 \cdot 1$ & 23 & $1: 2 \cdot 1$ & $52>50,54$ & $\underline{51>49>47,53}$ & $59>57(<)$ & $49,51>53$ & - & - & - \\
\hline M. $t b 2668 / 92$ & $c<t 16.7$ & $1: 1 \cdot 7$ & 23 & $1: 1 \cdot 9$ & $52>50,54$ & $\underline{51>49,53}$ & - & - & - & - & - \\
\hline M. $t b$ Canetti MNC1485 & $\ll \mathrm{t} 35 \cdot 0$ & $1: 3 \cdot 8$ & 23 & $1: 4 \cdot 0$ & $52>50>54$ & $\underline{51,53>49,55}$ & $59,61>57(<)$ & $\underline{51>49,53}$ & $59>57,61(<)$ & - & - \\
\hline M. $t b \mathrm{H} 37 \mathrm{Rv}$ & $c<t 17.5$ & $1: 1 \cdot 4$ & 23 & $1: 1 \cdot 4$ & $52>50,54$ & $\underline{51>49,53}$ & - & $\underline{51>49>47,53}$ & $59>57(<)$ & $52>50,54$ & - \\
\hline M. $t b \mathrm{H} 37 \mathrm{Ra}$ & $c \gg 25 \cdot 0$ & $1:$ trace & 23 & $1: 0 \cdot 03$ & $\underline{50>48,52>46}$ & - & $50>48,52(45)$ & - & - & - & $48,50>46,52(100)$ \\
\hline M. bovis MNC8 & $\ll \mathrm{t} 16 \cdot 2$ & $1: 3 \cdot 2$ & 23 & $1: 3 \cdot 3$ & $50,52>48$ & $\underline{49,51>47,53}$ & - & $49>47,51$ & - & - & - \\
\hline M. bovis MNC27 & $\ll \mathrm{t} 10 \cdot 0$ & $1: 3 \cdot 1$ & 23 & $1: 3 \cdot 2$ & $\underline{52>50>54}$ & $\underline{51>49,53}$ & - & - & - & - & - \\
\hline $\begin{array}{l}\text { M. bovis BCG Danish } \\
1331\end{array}$ & $c / t 8 \cdot 3$ & $1: 0 \cdot 42$ & 23 & $1: 0 \cdot 42$ & $\underline{50>52>54}$ & $\underline{51>}$ & - & - & - & - & - \\
\hline $\begin{array}{l}\text { M. bovis BCG } \\
\text { Danish MNC5 }\end{array}$ & $\mathrm{c} / \mathrm{t} 14 \cdot 5$ & $1: 0 \cdot 75$ & 23 & $1: 0 \cdot 74$ & $\underline{52>50>48,54}$ & $\underline{51>49,53}$ & - & $\underline{49>51>47}$ & $57>59(<)$ & - & - \\
\hline M. bovis BCG Glaxo 10-F & $\mathrm{c} / \mathrm{t} 10 \cdot 4$ & $1: 0 \cdot 25$ & 23 & $1: 0 \cdot 25$ & $\underline{50>52>54}$ & $49>$ & - & - & - & - & - \\
\hline $\begin{array}{l}\text { M. bovis BCG Pasteur } \\
1173 \mathrm{P} 2\end{array}$ & $\mathrm{c} / \mathrm{t} 10 \cdot 0$ & $1: 0 \cdot 25$ & 23 & $1: 0 \cdot 29$ & $\underline{52>48,54}$ & $51>49,53$ & - & - & - & - & - \\
\hline M. bovis BCG Tokyo 172 & $c / t 16.5$ & $1: 0 \cdot 25$ & 23 & $1: 0 \cdot 38$ & $\underline{52>50>46}$ & $51>49,53$ & $60>58>56(<)$ & $49>47,51$ & - & $\underline{50>52>48}$ & $50>48,52(19)$ \\
\hline $\begin{array}{l}\text { M. bovis BCG Tokyo } \\
172-\mathrm{V}\end{array}$ & $\mathrm{c} / \mathrm{t} 17 \cdot 0$ & $1: 0 \cdot 44$ & 23 & $1: 0 \cdot 46$ & $\underline{50,52>48,54}$ & $51>49>47,53$ & $60>62(<)$ & $\underline{49,51>47,53}$ & $57>59(<)$ & $\underline{50>48,52}$ & $50>48,52(26)$ \\
\hline M. microti OV248 & $c>t 25.0$ & $1: 0 \cdot 2$ & 23 & $1: 0 \cdot 25$ & $\underline{50>48,52>46}$ & $49>47,51$ & - & - & - & $\underline{46,48>44,50}$ & $44>46,48>42(43)$ \\
\hline M. kansasii 20-01 & $c / t 7 \cdot 6$ & $1: 5 \cdot 2$ & 21 & $1: 5 \cdot 2$ & $52>50,54$ & $\underline{51,53>49,55}$ & $59,61(<)$ & - & - & - & - \\
\hline M. kansasii 304 & $<\mathrm{t} 7 \cdot 0$ & $1: 6 \cdot 3$ & 21 & $1: 6 \cdot 3$ & $52>50,54$ & $\underline{51,53>49,55}$ & $59>61(<)$ & - & - & - & - \\
\hline M. kansasii 429 & $<\mathrm{t} 8 \cdot 0$ & $1: 5 \cdot 8$ & 21 & $1: 5 \cdot 6$ & $50,52>48$ & $\underline{51>49,53}$ & $59>57,61(<)$ & $\underline{49>47>45,51}$ & - & - & - \\
\hline $\begin{array}{l}\text { M. avium complex } \\
\text { KK41-24 }\end{array}$ & $<\mathrm{t} 23 \cdot 0$ & $1: 6 \cdot 3$ & 21 & $1: 8 \cdot 0$ & $52>50,54$ & $\underline{51>53>49}$ & $59>61(<)$ & $\underline{51>49,53}$ & - & $\underline{52>50,54}$ & $51>49,51(16)$ \\
\hline $\begin{array}{l}\text { M. avium complex } \\
\text { MNC10 }\end{array}$ & - & - & 21 & - & - & $\underline{51>49>47,53}$ & - & - & - & - & $51>49>47,51(16)$ \\
\hline
\end{tabular}

*Percentage in whole mycolate.

†In each series, the components are grouped in order of decreasing abundance. Major series are italicized and underlined. The cyclopropane rings in ketomycolates- 2 and -3 appear to be predominantly cis. It was not possible to determine the stereochemistry of the additional cyclopropane ring in ketomycolates-1.

$\ddagger(\mathrm{c})$ denotes cis-cyclopropyl group-containing series and $(\mathrm{t})$ denotes trans-cyclopropyl group-containing series.

$\$$ Figures in parentheses are percentages of three intra-chain group-containing species in each type of mycolates. $<$ denotes that the content is less than $10 \%$.

cyclopropane rings. MALDI-TOF/MS demonstrated that the type-3 methoxy- and ketomycolates each consisted of two series, one containing one oxygen function and one cis-double bond and the other with one oxygen function, one cis-double bond and one normally cis-cyclopropane ring. In the ketomycolate- 3 of the MAC strain, however, the cyclopropane ring was trans.

The exceptional methoxy- and ketomycolates- 1 of $M$. tuberculosis $\mathrm{H} 37 \mathrm{Ra}$ included $33 \%$ and $45 \%$, respectively, of homologues containing two cis-cyclopropane rings (Tables 3 and 4). MALDI-TOF/MS confirmed this estimation by giving two series of peaks (Fig. 3b), but these type- 1 dicyclopropyl methoxy- $\left(1+\mathrm{m}+\mathrm{n}+\mathrm{n}^{\prime}=\right.$ 46-52) and ketomycolates $\left(1+\mathrm{m}+\mathrm{n}+\mathrm{n}^{\prime}=48-50\right)$ were similar in size. As noted above, the type- 1 and type- 2 methoxy- and ketomycolates from the H37Rv and other
M. tuberculosis strains were all elongated $\left(1+\mathrm{m}+\mathrm{n}+\mathrm{n}^{\prime}\right.$ =55-60), when an additional double bond or cyclopropane group was present. The methoxy- and ketomycolates-3 of H37Ra apparently consisted exclusively of mycolates $\left(1+\mathrm{m}+\mathrm{n}+\mathrm{n}^{\prime}=46-52\right)$ containing one oxygen function, one cis-double bond and one ciscyclopropane ring. There was a clear distinction between the 15 varieties of mycolates produced by $M$. tuberculosis $\mathrm{H} 37 \mathrm{Rv}$ and the 9 varieties detected in the attenuated variant $\mathrm{H} 37 \mathrm{Ra}$ (Tables 2-4).

\section{Effect of cis/trans stereochemistry on mycolate chromatography}

The results for the silica gel chromatography of total mycolates from M. kansasii 304 are summarized in Table 5. Mycolates having trans-double bonds or trans- 
Table 5. Stereochemistry of double bonds and cyclopropane rings in different chromatographic fractions of $M$. kansasii mycolates

Silica gel column chromatography of total methyl mycolate fraction, eluting with diethyl ether/hexane $(6: 100, v / v)$. Each fraction was examined by ${ }^{1} \mathrm{H}-\mathrm{NMR}$ spectrometry.

\begin{tabular}{|c|c|c|c|c|c|c|}
\hline \multirow[t]{2}{*}{ Mycolate fraction } & \multirow[t]{2}{*}{ Fraction no. } & \multirow{2}{*}{$\begin{array}{l}\text { Yield } \\
(\mathrm{mg})\end{array}$} & \multicolumn{2}{|c|}{ Double bond } & \multicolumn{2}{|c|}{ Cyclopropane ring } \\
\hline & & & Content $(\%)$ & Nature* & cis & trans \\
\hline \multirow[t]{2}{*}{$\alpha$-Mycolate } & $a-1$ & 18 & $4 \cdot 5$ & cis/trans & 1 & $0 \cdot 06$ \\
\hline & $a-2,3,4$ & 85 & $5 \cdot 0$ & cis $\gg$ trans & 1 & $0 \cdot 04$ \\
\hline \multirow[t]{4}{*}{ Methoxymycolate } & $\mathrm{m}-1$ & 4 & $4 \cdot 4$ & cis $<$ trans & 1 & $1 \cdot 6$ \\
\hline & $\mathrm{m}-2$ & 25 & $5 \cdot 0$ & cis/trans & 1 & $1 \cdot 0$ \\
\hline & $\mathrm{m}-3$ & 20 & $5 \cdot 8$ & cis/trans & 1 & $0 \cdot 5$ \\
\hline & $m-4$ & 8 & $8 \cdot 4$ & cis $\gg$ trans & 1 & $0 \cdot 2$ \\
\hline \multirow[t]{4}{*}{ Ketomycolate } & $\mathrm{k}-1,2$ & 70 & $6 \cdot 8$ & cis $\ll$ trans & 1 & $7 \cdot 1$ \\
\hline & $\mathrm{k}-3,4$ & 30 & $6 \cdot 4$ & cis/trans & 1 & $5 \cdot 0$ \\
\hline & $\mathrm{k}-5$ & 10 & $8 \cdot 0$ & cis $>$ trans & 1 & $4 \cdot 0$ \\
\hline & $\mathrm{k}-6$ & $2 \cdot 5$ & $20 \cdot 0$ & cis $\gg$ & 1 & $1 \cdot 8$ \\
\hline
\end{tabular}

*Estimation of cis- and trans-double bond contents from ${ }^{1} \mathrm{H}-\mathrm{NMR}$ signal profiles. cis $>$ trans, more cis than trans; cis/trans, cis/trans ratio about $1 / 1$.

cyclopropane rings tended to elute faster than the corresponding mycolates containing cis unsaturations.

\section{DISCUSSION}

\section{Overall mycolate composition}

As shown in Table 1, the overall cis/trans ratios for mycolate cyclopropane rings were similar for strains of the same species. The ratios between the $\alpha$-, methoxyand ketomycolates, calculated from ${ }^{1} \mathrm{H}-\mathrm{NMR}$ signal areas, generally agreed well with the ratios between the weights recovered from chromatography, with exception of the M. tuberculosis H37Ra mycolates. This disagreement resulted from the assumption that each mycolate contained two functional groups, whereas a large proportion of the mycolates of this strain contained three functional groups, as seen in Tables 2, 3 and 4. Therefore, for this strain, the weight ratio given represents its actual mycolate ratio.

The mycolic acids from M. tuberculosis and M. bovis were distinguished from those of $M$. bovis BCG, $M$. microti, M. kansasii and MAC by details of chain length and other structural features (Tables 1-4).

\section{Distribution of major mycolates}

Small differences were noted in the mycolate ratios among the M. tuberculosis complex strains. Davidson et al. (1982) observed changes in the proportions of methoxy- and ketomycolates during cultivation of $M$. microti. An analogous phenomenon was noted in $M$. bovis BCG Tokyo; the ketomycolate content decreased and the methoxymycolate content increased as the cultivation was continued (Table 1), while the $\alpha$ - mycolate content remained almost constant. When the $\alpha$-mycolate content was compared with the oxymycolate (methoxy- + ketomycolate) content (Table 1), however, these M. tuberculosis strains gave values of about $1: 1$ (for M. tuberculosis H37Ra, on a weight basis). The Canetti strain, however, gave a slightly higher value and the two newly isolated Japanese clinical strains, $\mathrm{O}$ and $\mathrm{K}$, gave lower values. The lower $\alpha$-mycolate to oxymycolate ratios $(\sim 1: 0 \cdot 6)$ of these two recent clinical isolates were due to their low ketomycolate content. For the recent Swedish patient isolates $(9829 / 87,4610 / 91$, $2668 / 92)$, the ratios of $\alpha$-mycolates to oxymycolates were more in line $(\sim 1: 1)$ with other strains of $M$. tuberculosis. A previous report (Yuan et al., 1997), on 10 newly isolated USA strains, gave a mean $\alpha$-mycolate to oxymycolate ratio of $1: 0.77$, which is intermediate between the present results for the Japanese and Swedish strains. Mycolate ratios varied with cultivation time for M. bovis BCG Tokyo but the overall $\alpha$-mycolate to oxymycolate ratio was relatively constant $(\sim 1: 3.5)$ (Table 1). The remaining BCG preparations differed from BCG Tokyo, in that the same ratios were in the range $1: 1 \cdot 5$ to $1 \cdot 8$; a similar result $(1: 1 \cdot 66)$ was found for M. microti.

The mycolate compositions and/or stereochemistry of cyclopropane rings and double bonds reported by different authors do not always agree with each other and our present results. For example, it is reported that the proportion of cis/trans-groups for the mycolates from M. tuberculosis H37Rv is 1:0.02 (Yuan et al., 1997), whereas the corresponding value for our culture was 1:0.14 (Table 1 ). The trans-cyclopropane ring and trans-double bond contents of the methoxy- and ketomycolate of the H37Rv strain were reported (Yuan et 
al., 1997) to be less than $1: 0 \cdot 05$ and $1: 0 \cdot 2$, respectively, whereas the corresponding data for our culture were $1: 0 \cdot 32$ and $1: 1 \cdot 4$, respectively. Small differences in the cis/trans ratios of cyclopropane rings might be attributable to different chromatographic procedures. Mycolates with trans-double bonds and cyclopropane rings tended to move faster than the corresponding ones with cis-groups on silica gel chromatography (Table 5), so that the earlier chromatographic eluates might be richer in trans-groups. However, such a wide discrepancy may be due to laboratory selection or phenotypic changes. Thus, cultures bearing the same strain name should not always be considered to be identical, as illustrated by M. bovis BCG strains. Of the BCG strains, only the Tokyo strain produced a substantial amount of methoxymycolate, as reported previously (Minnikin et al., 1984b), whereas the others contained only a trace amount, detectable in ${ }^{1} \mathrm{H}-\mathrm{NMR}$ spectra (Table 1).

Our present results support the view that methoxy- and ketomycolates are biosynthetically related to each other (Dubnau et al., 1997; Yuan \& Barry, 1996; Yuan et al., 1997). Both the methoxy- and ketomycolates contained significant amounts of trans-double bonds and transcyclopropane rings, and the total chain lengths of the major mycolates in each of these two classes of the same strains were apparently the same. Although the methoxy- and ketomycolate content ratios varied with the cultivation period and in different preparations, the sum of the methoxymycolate content and the ketomycolate content versus the $\alpha$-mycolate content was almost always constant (Table 1), implying a close relationship between the two oxygenated mycolates. However, the trans-cyclopropane ring content was much higher in the ketomycolates than in the corresponding methoxymycolates and the same tendency was noted in the trans-double bond content, as shown in Tables 3 and 4. This does not suggest an immediate common precursor for the two oxygenated mycolates (Dubnau et al., 1997).

\section{Distribution of minor mycolates}

In general, molecular mass comparisons of the methoxy(Table 3) and ketomycolates (Table 4) indicated that the minor trans-mono-olefinic type- 2 mycolates were directly related to the major trans-mono-cyclopropyl type-1 mycolates, as were the corresponding minor cismono-olefinic type-3 and major cis-mono-cyclopropyl type- 1 . However, in the unusual type- 3 methoxy- and ketomycolates, the additional cyclopropane ring was normally cis even when the major type- 1 mycolates had trans-cyclopropane rings, as in the $M$. tuberculosis ketomycolates. The additional cyclopropane ring, however, was trans in the ketomycolates-3 of the MAC strains. Further studies will be needed to clarify the relationships of these type-2 and -3 oxygenated mycolates, having an additional cyclopropane ring, to the major established mycolate types.

It is interesting that the type-3 methoxy- and ketomycolates, with an additional cyclopropane ring, have $1+m+n+n^{\prime}$ values (Tables 3 and 4) around 48, 50 but the corresponding type- 2 mycolates have values of 57 , 59. These two classes are not interrelated, therefore, by a simple methylation step, converting a cis-double bond to a trans-double bond, with an adjacent methyl branch. It would be necessary to incorporate an elongation step at a key stage. These type- 2 mycolates perhaps share a common oxygenated di-cis-olefinic unsaturated precursor $\left(1+m+n+n^{\prime}=48,50\right)$ with the dicyclopropyl type1 oxygenated mycolates. In the case of the H37Ra strain, this postulated precursor may be simply methylated to give, successively, mycolates-3 (1 cis-double bond +1 cyclopropane ring) $\left(1+\mathrm{m}+\mathrm{n}+\mathrm{n}^{\prime}=48,50\right)$, mycolates1 (2 cis-cyclopropanes) $\left(1+\mathrm{m}+\mathrm{n}+\mathrm{n}^{\prime}=48,50\right)$. In the others, it appears that oxygenated mycolates-3 (1 cisdouble bond +1 cyclopropane ring $)\left(1+m+n+n^{\prime}=\right.$ $48,50)$, or a related component, are elongated before their cis-double bonds are converted into either ciscyclopropanes (type-1) or trans-double bonds with an adjacent methyl branch (type-2).

Related transformations are apparent in the $\alpha$-mycolate series (Table 2). A di-cis-olefinic precursor in H37Ra may be converted to type- 3 ( 1 cis-double bond +1 cyclopropane ring) and type-1 (di-cyclopropyl) mycolates. The H37Ra strain may also introduce another unsaturation in the type- 3 mycolates, with 1 cis-double bond +2 cyclopropane rings, but it cannot elongate or convert its $c i s$-double bonds to trans-double bonds with adjacent methyl branches. The attenuated H37Ra strain appears to be deficient in mycolate elongation and transdouble bond formation. Traces of both series of type-3 $\alpha$-mycolates were indicated in most strains of $M$. tuberculosis but the amounts were insufficient to allow full characterization.

The chain length of the $\alpha$-mycolates from the $M$. tuberculosis complex was shorter than that of the corresponding methoxy- and ketomycolates by $6-8$ methylene units. This is in accordance with previous views (Brennan \& Nikaido, 1995; Kremer et al., 2000) that distinct biosynthetic pathways operate for the $\alpha$ mycolate and for the oxygenated methoxy- and ketomycolates. In M. kansasii and the MAC, however, all $\alpha$-, methoxy- and ketomycolates had similar chain lengths. It was previously indicated (Brennan \& Nikaido, 1995) that the $\alpha$-mycolates did not have components with trans-cyclopropane rings and adjacent methyl branches. The present results showed that trans-cyclopropane rings were present in the $\alpha$-mycolate from M. kansasii and the MAC complex, although the proportions were extremely low compared with those in the two oxygenated mycolates. Small proportions of cis- and transdouble bonds were detected in all $\alpha$-mycolates investigated. Although the double bonds of $\alpha$-mycolate had mostly cis-stereochemistry, trans-isomers were substantial in the $\alpha$-mycolates from the Canetti and MAC strains (Table 2). An early ${ }^{1} \mathrm{H}-\mathrm{NMR}$ study (Minnikin \& Polgar, 1967) noted the presence of doublet at $\tau 9 \cdot 01$ $(\delta 0 \cdot 99)$, corresponding to a methyl branch adjacent to a trans-double bond, in the spectrum of the $\alpha$-mycolates from M. avium. 
The chain lengths $(1+\mathrm{m}+\mathrm{n}=47-51)$ of the novel transolefinic, cis-cyclopropyl $\alpha$-mycolate-2 (Table 2 ) from the M. tuberculosis Canetti strain are apparently comparable with those $(1+\mathrm{m}+\mathrm{n}=48-54)$ of the Canetti cis-cyclopropyl type-1 methoxy- and ketomycolates (Tables 3 and 4). It is tempting to suggest that the $\alpha$ mycolates- 2 of the Canetti strain may be related to possible precursors of methoxy- and ketomycolates. Oxygenated mycolates have been shown to arise by methylation of a precursor with a distal cis-double bond, followed by hydroxylation of the intermediate carbocation (Dubnau et al., 1997; Yuan \& Barry, 1996; Yuan et al., 1997). This intermediate carbocation could also lose a proton to give this type- $2 \alpha$-mycolate, having a trans-double bond and an adjacent methyl branch. It is notable that traces of similar type- $2 \alpha$-mycolates were detected in other strains of M. tuberculosis (see Results). The type- 2 trans-olefinic, cis-cyclopropyl $\alpha$-mycolates from the MAC strains (Table 2) may similarly be related to possible precursors of ketomycolates-1. Further clarification of any possible relationship of these type- 2 $\alpha$-mycolates with oxymycolates must await a detailed structural comparison with the methoxy- and ketomycolates, particularly the location of double bonds and cyclopropane rings.

\section{Mycolates and virulence}

One of the most striking differences in the mycolate profiles is the clear distinction seen between the attenuated M. tuberculosis $\mathrm{H} 37 \mathrm{Ra}$ and the other virulent strains, including the $\mathrm{H} 37 \mathrm{Rv}$ type strain. The possible presence of unusual dicyclopropyl methoxy- and ketomycolates in $M$. tuberculosis $\mathrm{H} 37 \mathrm{Ra}$ had been previously indicated by Takayama et al. (1979) and this study has substantiated this finding (Tables 3 and 4). The H37Rv strain appears capable of synthesizing a total of at least 15 distinct homologous mycolate series, but the H37Ra strain has only 7 such series (Tables $2-4$ ). As indicated above, the H37Ra variant appears to have deficiencies in both mycolate elongation and the transformation of cis-double bonds to trans-double bonds, with an adjacent methyl branch. There is, however, a marked proficiency in H37Ra for the production of mycolates with an additional cyclopropane ring, as exemplified by the $\alpha$-mycolate- 3 (Table 2 ) and methoxyand ketomycolates- 1 and -3 (Tables 3 and 4). Detailed studies will be needed to determine the significance and interrelation of these unusual mycolates. The distinct mycolate composition of the attenuated H37Ra variant may contribute to its lack of virulence but it also has profiles of free lipids that are deficient in comparison with H37Rv (Minnikin et al., 1986). The single $M$. tuberculosis Canetti variant, with smooth colony morphology, has an unusual mycolate profile but it is a virulent strain.

The attenuated strains of $M$. bovis BCG have variable mycolate composition (Tables 1-4); the clearest difference is the trace amount of methoxymycolates in the Danish, Glaxo and Pasteur strains, as compared with the Tokyo strain (Minnikin et al., 1984b). The Tokyo strains are notable in having increased proportions of oxygenated mycolates, including methoxymycolates- 1 and -3 (Table 3 ) and ketomycolates-3 (Table 4) with an additional cyclopropane ring. The vole bacillus, $M$. microti, is not a human pathogen and its mycolates are notable only in having enhanced proportions of methoxy- and ketomycolates-3, with the additional cyclopropane ring (Tables 3 and 4). The BCG strains, in particular, have been repeatedly subcultured so that it is difficult to make meaningful comparisons with modern virulent strains. The same comment is also pertinent for M. tuberculosis H37Rv and H37Ra.

\section{Conclusions}

The present systematic study has clearly shown, for the first time, that there is considerable variation in the mycolate composition of members of the M. tuberculosis complex and related mycobacteria. For example, well-studied reference strains, such as Aoyama B and MNC1397, showed the expected patterns of dicyclopropyl $\alpha$-mycolate, and two series of methoxy- and ketomycolates with cis- and trans-cyclopropane rings. However, in addition to these five expected mycolate series, these two strains produced an extra seven and nine minor homologous series, respectively (Tables $2-4$ ).

Some of the minor mycolate series are undoubtedly biosynthetic precursors of the major types, examples being $\alpha$-mycolates-3 (1 cis-double bond and 1 ciscyclopropane) and the methoxy- and ketomycolates-2 and -3 with single cis-or trans-double bonds. Others, such as the cis-cyclopropyl, trans-olefinic $\alpha$-mycolates- 2 found in the Canetti and MAC strains, may be 'missing links', possibly related to precursors of the oxygenated mycolates as detailed above. It must be stressed, however, that the characterization of a mycolate series, which superficially could be transformed to another, does not confirm it as a direct precursor. The key transformation may have happened earlier, perhaps at the meromycolate stage, with both substrate and product subsequently being transformed into complete mycolates.

The clear identification of mycolate series with additional cyclopropane rings raises many intriguing questions. In some cases, these mycolates are elongated, as for the tricyclopropyl $\alpha$-mycolates- 1 (Table 2) and the dicyclopropyl methoxy- and ketomycolates-1 and -2 (Tables 3 and 4). In other series, such as the cisunsaturated dicyclopropyl $\alpha$-mycolates- 3 (Table 1 ) and the cis-unsaturated monocyclopropyl methoxy- and ketomycolates-3, the chains are not extended. An understanding of the true interrelation of these novel mycolates must await further studies, including precise structural analysis. The presence of an additional point of unsaturation, and increased chain length, in these mycolates must affect how they pack together in the mycobacterial outer membrane (Minnikin, 1991; Brennan \& Nikaido, 1995; Draper, 1998) and a specific role for these minor components must not be ruled out. 
The overall biosynthetic pathways to mycolic acids and other key mycobacterial cell envelope lipids are starting to be intensively studied using genetic approaches (Kremer et al., 2000). The novel mycolates, highlighted in this paper, will provide valuable signposts to correlate with such biosynthetic studies.

\section{ACKNOWLEDGEMENTS}

D.E.M. was funded by Medical Research Council Cooperative (49343) and Project (49338) grants; M.R. was supported by the Oscar II Jubilee Fund of the Swedish Heart and Lung Foundation.

\section{REFERENCES}

Brennan, P. J. \& Nikaido, H. (1995). The envelope of mycobacteria. Annu Rev Biochem 64, 29-63.

Daffé, M. \& Draper, P. (1998). The envelope layers of mycobacteria with reference to their pathogenicity. Adv Microb Physiol 39, 131-203.

Davidson, L. A., Draper, P \& Minnikin, D. E. (1982). Studies on the mycolic acids from the walls of Mycobacterium microti. J Gen Microbiol 128, 823-828.

Draper, P. (1998). The outer parts of the mycobacterial envelope as permeability barriers. Front Biosci 3, 1253-1261.

Dubnau, E., Lanéelle, M. A., Soares, S., Benichou, A., Vaz, T., Promé, D., Promé, J. C., Daffé, M. \& Quémard, A. (1997). Mycobacterium bovis BCG genes involved in the biosynthesis of cyclopropyl keto and hydroxy mycolic acids. Mol Microbiol 23, 313-322.

Hamid, M. E., Minnikin, D. E. \& Goodfellow, M. (1993). A simple chemical test to distinguish mycobacteria from other mycolic acid-containing actinomycetes. J Gen Microbiol 139, 2203-2213.

Hashimoto, N., Aoyama, T. \& Shioiri, T. (1981). New methods and reagents in organic synthesis 14 . A simple efficient preparation of methyl esters with trimethylsilyldiazomethane $\left(\mathrm{TMSCHN}_{2}\right)$ and its application to gas chromatographic analysis of fatty acids. Chem Pharm Bull 29, 1475-1478.

Jenkins, I. D. \& Goren, M. B. (1986). Improved synthesis of cord factor analogues via the Mitsunobu reaction. Chem Phys Lipids 41, 225-235.

Kremer, L., Baulard, A. R. \& Besra, G. S. (2000). Genetics of mycolic acid biosynthesis. In Molecular Genetics of Mycobacteria, pp. 173-190. Edited by G. F. Hatfull \& W. R. Jacobs, Jr. Washington DC: American Society for Microbiology.

McNeil, M. R. \& Brennan, P. J. (1991). Structure, function and biogenesis of the cell envelope of mycobacteria in relation to bacterial physiology, pathogenesis and drug resistance: some thoughts and possibilities arising from recent structural information. Res Microbiol 7th Forum 142, 451-463.

McNeil, M. R., Daffé, M. \& Brennan, P. J. (1991). Locations of the mycolyl ester substituents in the cell wall of mycobacteria. J Biol Chem 266, 13217-13223.
Minnikin, D. E. (1991). Chemical principles in the organization of lipid components in the mycobacterial cell envelope. Res Microbiol 7 th Forum 142, 423-427.

Minnikin, D. E. \& Polgar, N. (1967). Mycolic acids from human and avian tubercle bacilli. Chem Commun 916-918.

Minnikin, D. E., Minnikin, S. M., Parlett, J. H., Goodfellow, M. \& Magnusson, M. (1984a). Mycolic acid patterns of some species of Mycobacterium. Arch Microbiol 139, 225-231.

Minnikin, D. E., Parlett, J. H., Magnusson, M., Ridell, M. \& Lind, A. (1984b). Mycolic acid patterns of representatives of $\mathrm{Myco-}$ bacterium bovis BCG. J Gen Microbiol 130, 2733-2736.

Minnikin, D. E., Parlett, J. H., Dobson, G., Goodfellow, M., Magnusson, M. \& Ridell, M. (1986). Lipid profiles of members of the Mycobacterium tuberculosis complex. In Mycobacteria of Clinical Interest, pp. 75-78. Edited by M. Casal. Amsterdam: Elsevier.

Paul, T. R. \& Beveridge, T. J. (1992). Re-evaluation of envelope profiles and cytoplasmic ultrastructure of mycobacteria processed by conventional embedding and freeze-substitution protocols. $J$ Bacteriol 174, 6508-6517.

Paul, T. R. \& Beveridge, T. J. (1994). Preservation of surface lipids and determination of ultrastructure of Mycobacterium kansasii by freeze-substitution. Infect Immun 62, 1542-1555.

Qureshi, N., Takayama, K., Jordi, H. C. \& Schnoes, H. K. (1978). Characterization of the purified components of a new homologous series of alpha-mycolic acids from Mycobacterium tuberculosis H37Ra. J Biol Chem 253, 5411-5417.

Takayama, K., Qureshi, N., Jordi, H. C. \& Schnoes, H. K. (1979). Separation of homologous series of mycolic acids from Mycobacterium tuberculosis $\mathrm{H} 37 \mathrm{Ra}$ by high performance liquid chromatography. In Biological/Biomedical Applications of Liquid Chromatography, pp. 91-101. Edited by G. L. Hawk. New York: Marcel Dekker.

Watanabe, M., Yamada, Y., Iguchi, K. \& Minnikin, D. E. (1994). Structural elucidation of new phenolic glycolipids from Mycobacterium tuberculosis. Biochim Biophys Acta 1210, 174-180.

Watanabe, M., Ohta, A., Sasaki, S. \& Minnikin, D. E. (1999). Structure of a new glycolipid from the Mycobacterium aviumMycobacterium intracellulare complex. J Bacteriol 181, 2293-2297.

Yuan, Y. \& Barry, C. E., III (1996). A common mechanism for the biosynthesis of methoxy and cyclopropyl mycolic acids in Mycobacterium tuberculosis. Proc Natl Acad Sci USA 93, 12828-12833.

Yuan, Y., Crane, D. C., Musser, J. M., Sreevatsan, S. \& Barry, C. E., III (1997). MMAS-1, the branch point between cis- and transcyclopropane-containing oxygenated mycolates in $\mathrm{Myco-}$ bacterium tuberculosis. J Biol Chem 272, 10041-10049.

Received 29 December 2000; revised 22 February 2001; accepted 26 March 2001. 